\title{
ASPECTO E FATO: Um Passeio Pelo Tempo
}

\author{
Geraldo Mattos
}

nunciado mínimo, o periodo é primeiro um trabalho mental que parte da resposta a uma prévia indagação do falante:

- De que é que eu vou falar?

A resposta vai dar um germe do fato, que pode ser manifestado por um verbo, por um substantivo ou por um adjetivo conforme a língua de que se trate, ainda que a maioria delas apresente verbos. Devo justificar a palavra fato, que escolhi para indicar o ponto de partida do periodo. Eu poderia talvez adotar a palavra acontecimento, mas a descartei, pensando em verbos que veiculam conteúdos que nunca indicam o que acontece. Considere-se o período abaixo:

Ela é bonita.

Quer parecer-me que se veicula um fato, nunca um acontecimento: o fato de que ela é bonita.

A esse fato pode agregar-se mais de um morfema ou mais de um vocábulo para circunstanciar o dado que se pretende descrever. Esse conjunto de morfemas ou vocábulos vai implicar uma rede de significados que constitucm o modelo fatual de cada língua. Como me interessa mais o fato das línguas indo-européias, detenho-me nelas mais longamente nesta conversa comigo

- Universidade Federal do Paraná. 
mesmo, em que acolho gostosamente a companhia de possiveis leitores. Essas linguas podem apresentar as circunstâncias de tempo, modo e aspecto, manifestadas todas por morfemas do verbo.

O tempo é a circunstância em que o diálogo marca o momento do fato $\mathrm{e}$ a escolha da forma do verbo depende do momento da fala:

\section{Fato simultâneo: tempo presente \\ Diálogo Fato anterior: tempo passado \\ Fato posterior: tempo futuro}

Num gráfico, a linha do tempo, dependente do diálogo, tem apenas uma interseç̧ão, que marca o presente da fala ( $\mathrm{P}$ : presente):

Passado
O modo é a circunstância em que o falante julga o fato e o qualifíca.
Observe-se que o julgamento do falante é puramente subjetivo, podendo acon-
tecer que dois falantes interpretem o fato diferentemente. Todo modo é um
informe dado no nivel do vocábulo e nenhuma relação guarda com o fato que
se veicula. Assim, se determinada língua tiver o modo da experiência (direta ou
indireta), a própria forma verbal vai indicar se o fato que se conta é um
acontecimento testemunhado pelo falante ou uma notícia que lhe foi passada.
Noutras palavras, o modo do verbo indica a maneira de o falante interferir com
o fato. O qualificativo que mais aparece nas línguas neolatinas incide sobre a
ocorrência do fato:

\section{Modo}

Fato efetivo: Indicativo

Fato eventual: Subjuntivo

É preciso considerar ainda que o modo pode ser condicionado ou incondicionado. Assim, o subjuntivo do português é condicionado ao tipo de pcríodo: salvo algum condicionamento vocabular (anteposta, a palavra talvez implica o subjuntivo), nunca pode aparecer em periodo assertivo e algumas de suas formas requerem ainda o período subordinado. Quando há mais de um modo (é o caso do português, que tem dois: a eventualidade e a realidade), é incondicionado aquele que possui formas indicativas. $\mathrm{O}$ modo condicionado é apenas uma variante sintática: assim, o nosso presente do subjuntivo é uma variante periodal do presente do indicativo e marca o periodo jussivo, enquanto o futuro do subjuntivo é uma variante periodal do perfeito do indicativo e 
assinala o passado anterior a um futuro. Ao contrário do português, o Bela Coola, língua indígena norte-americana, tem dois modos, ambos incondicionados: o da experiência e o da visibilidade. À falta da categoria de tempo, é claro que a época do fato deve ser induzida dos significados de modo.

$O$ aspecto é a circunstância em que o fato é discriminado pelas características de sua presença no mundo e a escolha da forma verbal depende delas. Ou seja, numa linguagem mais simples: $o$ aspecto do verbo é o tempo do fato. Num gráfico, a linha do tempo do fato vai apresentar duas intersecçōes, que denotam o presente do fato, que é o intervalo entre o início (O: origem) e o término do fato (D: destino), implicando uma visão diferentc da realidade, dado que o futuro fíca às costas e o passado à frente:

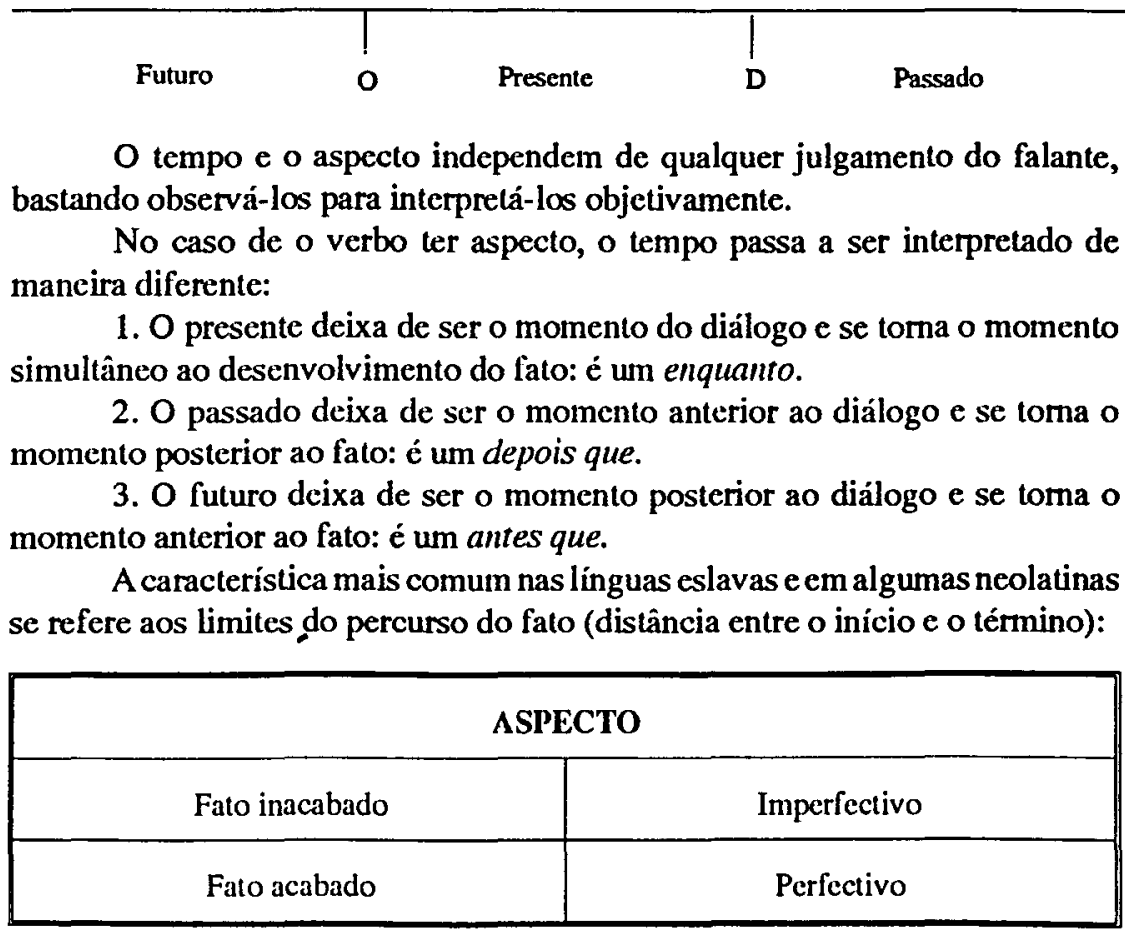

O limite entre o fato inacabado e o acabado aparece claramente no gráfico da linha de tempo do fato, em que a passagem do inacabado para o acabado fica marcada pelo destino: 
Na falta da categoria de tempo, o falante deve induzir das categorias existentes a época em que se verifica o fato. $O$ aspecto ou o modo ficam com a função secundária de marcar o momento do diálogo. No caso do aspecto, tem-se:

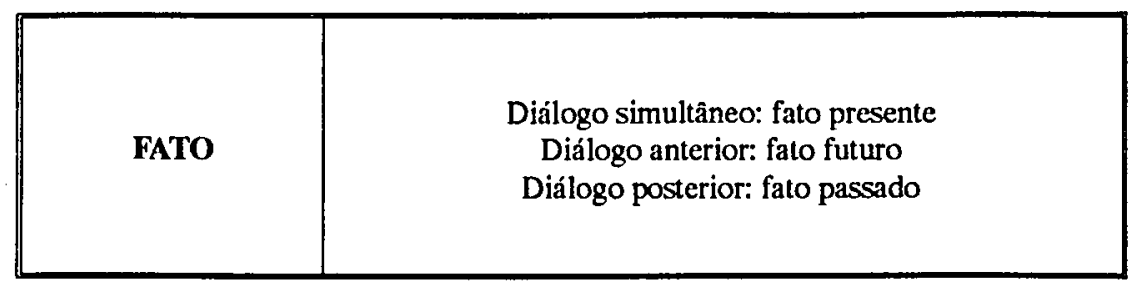

Neste caso, os tempos passado, presente e futuro perdem a existência morfológica e devem ser inferidos do conjunto das circunstâncias do aspecto.

É preciso observar que a simultaneidade do conjunto de morfemas de tempo, aspecto ou modo gera um paradigma: um conjunto de formas que constituem uma única palavra. Assim, as formas digo, dizia, diga, dissesse, disse, dissera, disser e dissesse (é intencional a forma repetida) representam oito vocábulos, mas apenas uma palavra, como o pode comprovar qualquer dicionário. Outra rede qualquer de morfemas, que meramente produza formas derivadas de uma palavra, originando outras tantas, nada tem que ver com a circunstância de aspecto. Esse fenômeno ocorre em línguas eslavas e germânicas, mais naquelas que nestas, e também em Esperanto.

É fácil provar que se trata de várias palavras: mais da metade desses novos verbos exigem um objeto no acusativo ou em outro caso, conforme a sintaxe da lingua, e podem, por isso, ter a passiva correspondente, quando se tratar de um objeto direto.

Parece haver um critério seguro para distinguir o fenômeno lingüístico morfológico do puramente semântico: se duas formas gerarem exatamente o mesmo conjunto de vocábulos, elas devem ser consideradas palavras diversas, sendo puramente semântico, nunca morfológico, o relacionamento significativo que elas manifestam entre si. Considerem-se estas formas infinitivas:

Iri: ir.

Ekiri: começar a ir - partir.

Esti: ser / estar / ficar [locativo] / haver [impessoal]

Ekesti: tornar-se / ficar [estado]

Poder-se-ia pensar que o segundo e o quarto verbo (ekiri, ekesti) constituem apenas o aspecto inceptivo do primeiro e do terceiro, respectivamente. Seria um erro, porque todos repetem o mesmo paradigma, forma por forma. Por esse motivo, cabe distinguir o aspecto do fato, que é um fenômeno de origem morfológica, da classe do fato, de origem puramente semântica. Com isso, 
torna-se sumamente penoso ou talvez impossivel estudar simultaneamente o aspecto do fato e a sua classe.

Com base nesse mesmo critério, devemos concluir que o aspecto de inacabamento do português apresenta três variantes, puramente semânticas:

1. Variante durativa: estar.

2. Variante inceptiva: $i r$.

3. Variante freqüentativa: andar.

É curioso que os verbos típicos de cada variante, citados acima como exemplos, sejam adotados pela língua para permitir a outros verbos os significados respectivamente durativo, inceptivo ou freqüentativo: estar estudando, ir estudar, andar estudando. Como já possucm respectivamente os aspectos durativo, inceptivo e freqüentativo, esses verbos podem juntar-se a todos os outros, exceto a eles mesmos.

O paradigma verbal pode aparecer com as categorias de tempo, modo e aspecto, com duas delas ou apenas com uma.

O latim trabalha com as très categorias, enquanto o português se limita a duas: aspecto c modo. É elucidativo que se reveja esse processo evolucional, que levou o sistema verbal latino à perda da categoria de tempo, porque nos vem dele a certeza de que as linguas encerram armadilhas sutis e o bom resultado da pesquisa depende de se colocar o fenômeno estudado dentro do campo maior a que pertence: em língua, a explicação de um elemento é sempre um dado do respectivo conjunto. $O$ exemplo que me parece clássico é o do estudo exaustivo e inteiramente inútil do presente contínuo da lingua inglesa. E por um motivo singelo: essa forma verbal não existe. Trata-se apenas do verbo to be, acrescido de um predicativo, cujo ocupante é um gerúndio, construindo uma sentença copulativa. Análise absolutamente idêntica se deve dar também ao fenômeno similar da língua portuguesa, em que as sentenças seguintes têm a mesma estrutura sintática (S: sujeito, V: verbo, P: predicativo):

O menino estå contente.

O menino está cantando.

S V P

Para evitar esses tropeços, o ideal é sempre estudar o conjunto inteiro das formas paradigmáticas, separando sempre o complexo de formas que veiculam significados por meio de afixos de qualquer outro complexo de formas que manifestem significados por meio de vocábulos: quase sempre, o nivel vocabular, formado por morfemas, difere do nível locucional, formado por vocábulos. É preciso lembrar, entretanto, que o processo afixal pode fornecer verbos que 
indicam classes de fato, nunca necessariamente tempos, modos ou aspectos do fato.

Além desse erro de interpretação da sentença, ocorre ainda que pouco interesse desperta o estudo das restrições existentes em cada língua, quase nunca universais, porque dependem de fatores variados:

1. Restrições naturais:

Independem das línguas e constituem universalidades. O fatoré o próprio comportamento dos seres do mundo:

*A parede cacareja.

*The wall clucks.

* La muro kokerikas.

\section{Restrições culturais:}

Dependem da comunidade lingüistica e constituem possibilidades. $O$ fator é a classificação diferente dos seres do mundo:

*A menina é contente.

*I am knowing the lesson. [Eu estou sabendo a lição.]

* Mi estas scianta la lecionon. [Eu estou sabendo a lição.]

\section{Restrições eventuais:}

Dependem da língua e constituem particularidades, ficando sujeitas aos azares do processo evolutivo. $O$ fator é a tradição:

*O menino artependeu.

*I killed me. [Eu me matei.]

*Kanti estas bona. [Cantar é bom.]

O dialeto mineiro tornou intransitivos ou transitivos muitos dos verbos essencialmente reflexivos da língua comum, comprovando assim o início de um processo evolutivo de uma das eventualidades da língua:

O menino arrependeu.

... queixar o desprezo da morena. (Drummond.) 
E volto ao assunto deste estudo, assinalando a desvantagem de uma conversa consigo mesmo: a digressão entra despercebida. E me desculpo desta, longa, mas oportuna...

O sistema verbal latino era complexo:

\begin{tabular}{|c|c|c|c|c|c|}
\hline & SPECTO & \multicolumn{2}{|c|}{ IMPERFECTIVO } & \multicolumn{2}{|c|}{ PERFECTIVO } \\
\hline & MODO & INDICATIVO & SUBUUNTIVO & SUBUUNTIVO & INDICATIVO \\
\hline $\mathbf{T}$ & Presente & $\begin{array}{l}\text { dico } \\
\text { amo }\end{array}$ & $\begin{array}{l}\text { dicam } \\
\text { amem }\end{array}$ & $\begin{array}{l}\text { dixerim } \\
\text { amauerim }\end{array}$ & $\begin{array}{c}\text { dixi } \\
\text { amaui }\end{array}$ \\
\hline $\mathbf{M}$ & Passado & $\begin{array}{l}\text { dicebam } \\
\text { amabam }\end{array}$ & $\begin{array}{l}\text { dicerem } \\
\text { amarem }\end{array}$ & $\begin{array}{l}\text { dixissem } \\
\text { amauissem }\end{array}$ & $\begin{array}{c}\text { dixeram } \\
\text { amaueram }\end{array}$ \\
\hline 0 & Futuro & $\begin{array}{l}\text { dicam } \\
\text { amabo }\end{array}$ & - & - & $\begin{array}{c}\text { dixero } \\
\text { amauero }\end{array}$ \\
\hline
\end{tabular}

Nesse estado, o latim dispunha de um equilíbrio perfeito no sistema: o paralelismo era total, incluindo o das próprias lacunas. O latim vulgar lusitânico, com mais certeza o tardio, modificou ligeiramente esse sistema, introduzindo o primeiro desequilibrio, fator de evolução. Houve a perda do futuro imperfeito $e$ se identificaram completamente as formas que se distinguiam apenas pela primeira pessoa do singular (dixerim e dixero, amauerim e amauero), além da perda do morfema regular de aspecto: 


\begin{tabular}{|c|c|c|c|c|c|}
\hline \multirow{2}{*}{\multicolumn{2}{|c|}{$\begin{array}{c}\text { ASPECTO } \\
\text { MODO }\end{array}$}} & \multicolumn{2}{|c|}{ MPERFECTIVO } & \multicolumn{2}{|c|}{ PERFECTIVO } \\
\hline & & INDICATIVO & SUBJUNTIVO & SUBUNTIVO & INDICATIVO \\
\hline $\begin{array}{l}\mathbf{T} \\
\mathbf{E}\end{array}$ & Presente & $\begin{array}{l}\text { dico } \\
\text { amo }\end{array}$ & $\begin{array}{l}\text { dicam } \\
\text { amem }\end{array}$ & $\begin{array}{l}\text { dixerim } \\
\text { amarim }\end{array}$ & $\begin{array}{l}\text { dixi } \\
\text { amai }\end{array}$ \\
\hline $\begin{array}{l}\mathbf{M} \\
\mathbf{p}\end{array}$ & Passado & $\begin{array}{l}\text { dicebam } \\
\text { amabam }\end{array}$ & $\begin{array}{l}\text { dicerem } \\
\text { amarem }\end{array}$ & $\begin{array}{l}\text { dixissem } \\
\text { amassem }\end{array}$ & $\begin{array}{l}\text { dixeram } \\
\text { amaram }\end{array}$ \\
\hline $\mathbf{0}$ & Futuro & $\begin{array}{l}- \\
-\end{array}$ & - & - & $\begin{array}{l}\text { dixerim } \\
\text { amarim }\end{array}$ \\
\hline
\end{tabular}

O romanço galego-português distanciou-se ainda mais do latim clássico, acentuando as diferenças, pois eliminou as formas subjuntivas que produziriam homonimias totais ou parciais no sistema finito do verbo, consideradas insuportáveis, mas tolerando-as entre as formas finitas e infinitas (futuro perfectivo e infinitivo dos verbos regulares): 


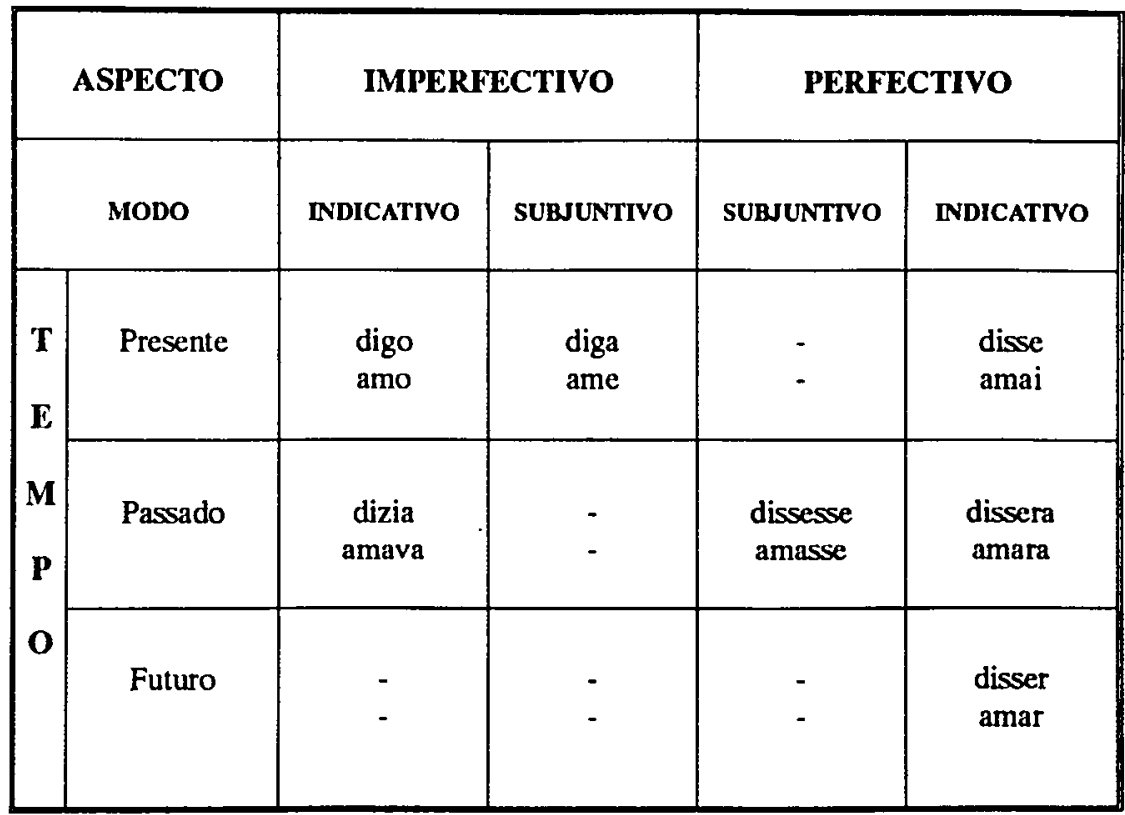

O romanço foi violentamente atingido pela homonimia e eliminou-a pelo método mais singelo: abandonou duas das quatro formas ambiguas. Se o sistema latino entrasse completo na língua portuguesa, os verbos regulares (todos, menos dezessete) teriam as mesmas formas para o imperfeito do subjuntivo, o perfeito do subjuntivo, o futuro do subjuntivo $c$ ainda o infinitivo. As duas últimas se mantiveram, distintas apenas nos verbos irregulares:

Se eu amar - futuro do subjuntivo.

Para eu amar - infinitivo.

Se eu disser - futuro do subjuntivo.

Para eu dizer - infinitivo.

O desequilibrio do sistema verbal do romanço teve de ser eliminado no galego-português (c nas demais linguas neolatinas): o sistema foi reformulado, desaparecendo inteiramente o futuro, recriado por meio de locuçōes verbais que se apuseram dentro do novo arranjo em português e passaram a participar dele nas outras línguas românicas. $O$ futuro do presente e o do pretérito são criaçōes românicas e a lingua portuguesa os mantém ainda agora como formas compostas por auxiliares: 
Amarei - amar hei [verbo auxiliar haver].

Amaria - amar ia [verbo auxiliar ir, do ponto de vista sincrônico].

A melhor prova desse estatuto morfológico, corroborada ainda pela prosódia do verbo principal, é a possibilidade da mesóclise com essas formas verbais:

Amar-te-ei.

Amar-te-ia.

Efetivamente, se o futuro do presente e o do pretérito fossem apenas palavras, nunca seria legítimo dividi-las.

A novidade principal foi o desaparecimento do tempo, embora nenhum gramático se tenha dado conta disso:

\begin{tabular}{||c|c|c|c|c|}
\hline \multirow{2}{*}{ ASPECTO } & \multicolumn{2}{|c|}{ INACABADO } & \multicolumn{2}{c|}{ ACABADO } \\
\hline MODO & EFETIVO & EVENTUAL & EVENTUAL & EFETIVO \\
\hline PROXIMO & $\begin{array}{c}\text { digo } \\
\text { amo }\end{array}$ & $\begin{array}{c}\text { diga } \\
\text { ame }\end{array}$ & $\begin{array}{c}\text { disser } \\
\text { amar }\end{array}$ & $\begin{array}{c}\text { disse } \\
\text { amei }\end{array}$ \\
\hline REMOTO & $\begin{array}{c}\text { dizia } \\
\text { amava }\end{array}$ & $\begin{array}{c}\text { dissesse } \\
\text { amasse }\end{array}$ & $\begin{array}{c}\text { dissesse } \\
\text { amasse }\end{array}$ & $\begin{array}{c}\text { dissera } \\
\text { amara }\end{array}$ \\
\hline
\end{tabular}

Assim, a lingua portuguesa trabalha com um par de significados de aspecto (fato inacabado contra fato acabado) e dois pares de significados de modo (fato próximo contra fato remoto e fato efetivo contra fato eventual). $O$ inacabado se realiza por uma das variantes durativa, inceptiva ou freqüentativa, enquanto o acabado é o passado do fato, que pode ocorrer agora, antes ou depois. O próximo manifesta o fato certo ou provável, enquanto o remoto constitui um modo impeditivo, por haver algum fator que inibe o falante de usar a forma próxima, e manifesta o fato impossivel ou improvável no momento da fala. Excluo desse quadro os futuros, por serem conjuntos locucionais, e o imperativo afirmativo de segunda pessoa, por serem variantes das respectivas pessoas da forma eventual (presente do subjuntivo), sujeito ao condicionamento de ini- 
ciarem ou poderem iniciar o periodo. Basta um exemplo dessas variantes imperativas:

Sê be-vindo!

Bem-vindo sejas!

E parece inaceitável qualquer destes periodos:

Bem-vindo sê!

Sejas bem-vindo!

O novo sistema trouxe novidades importantes:

1. Deslocou uma forma indicativa para a subjuntiva, transformando o modo de incondicionado em condicionado e de cfetivo em eventual, importando o significado de um passado no futuro:

\begin{tabular}{|c|c|c|}
\hline FORMAS & SIGNIFICADO DO ROMANÇO & $\begin{array}{c}\text { SIGNIFICADO DO ARCAICO } \\
\text { E DO MODERNO }\end{array}$ \\
\hline disser & eu terei dito \\
amar & eu terei amado & $\begin{array}{c}\text { no caso de eu dizer } \\
\text { no caso de eu amar }\end{array}$ \\
\hline
\end{tabular}

Com essa mudança, o indicativo perdeu uma forma, enquanto o subjuntivo ficou com uma a mais.

2. Transformou uma forma unívoca em ambigua, porque a forma acabada eventual remota passou a ocupar a vaga deixada ao se eliminar a homonimia e se tornou também inacabada eventual remota. De fato, o subjuntivo perfectivo passou a ser usado também como imperfectivo:

\begin{tabular}{|c|c|c|}
\hline FORMAS & SIGNIFICADO DO ROMANÇO & $\begin{array}{c}\text { SIGNIFICADO DO ARCAICO } \\
\text { E DO MODERNo }\end{array}$ \\
\hline dissesse & no caso de eu dizer & $\begin{array}{c}\text { [quis que] dissesse } \\
\text { no caso de dizer }\end{array}$ \\
\hline amasse & no caso de eu amar & $\begin{array}{c}\text { [quis que] amasse } \\
\text { no caso de amar }\end{array}$ \\
\hline
\end{tabular}


Tanto quanto eu sei, essa homonimia é desprezada por lingüistas e gramáticos, exigindo por isso uma justificativa. Com o deslocamento citado no primeiro item, o eventual próximo passou a dispor de duas formas (no caso, diga e disser, ame e amar), nenhuma delas podendo ser trocada pela outra, salvo no caso explicado adiante:

Espero que ele me diga a verdade.

Espero que ela me ame.

Agradecerei, se ele me disser a verdade.

Agradecerei, se ela me amar.

*Espero que ele me disser a verdade.

*Espero que ela me amar.

*Agradecerei, se ele me diga a verdade.

*Agradecerei, se ela me ame.

Agora, se trocarmos o modo incondicional pelo condicional, as formas verbais se repetem sem nenhuma agramaticalidade:

Esperei que ele me dissesse a verdade.

Esperei que ela me amasse.

Agradeceria, se cle me dissesse a verdade.

Agradeceria, se ela me amasse.

Com isso, vemos que as formas eventuais próximas se distinguem nitidamente, acarretando a troca comumente a agramaticalidade do enunciado. Portanto, se a forma eventual remota pode fazer par com cada uma das próximas, infere-se que deve tratar-se de uma homonímia, dado que duas coisas iguais a uma terceira deveriam ser também iguais entre si: é a lógica da redução ao absurdo. Eu me apóio na lógica: se corresponderem a duas formas nitidamente diferentes, duas formas aparentemente idênticas devem ser também diferentes.

Acresce ainda que a mesma homonímia se estendeu às formais frasais do verbo, resultando disso um equilibrio perfeito no sistema verbal. Enquanto as formas oracionais ou finitas do verbo veiculam fatos, as formas frasais, efetivas ou eventuais, indicam apenas circunstâncias de um fato, nunca um fato: 


\begin{tabular}{|c|c|c|c|c||}
\hline \multirow{2}{*}{ ASPECTO } & \multicolumn{2}{|c|}{ INACABADO } & \multicolumn{2}{c||}{ ACABADO } \\
\hline MODO & Efetivo & Eventual & Eventual & Efetivo \\
\hline Próximo & $\begin{array}{c}\text { digo } \\
\text { amo }\end{array}$ & $\begin{array}{l}\text { diga } \\
\text { ame }\end{array}$ & $\begin{array}{c}\text { disser } \\
\text { amar }\end{array}$ & $\begin{array}{c}\text { disse } \\
\text { amai }\end{array}$ \\
\hline Remoto & $\begin{array}{c}\text { dizia } \\
\text { amava }\end{array}$ & $\begin{array}{c}\text { dissesse } \\
\text { amasse }\end{array}$ & $\begin{array}{c}\text { dissesse } \\
\text { amasse }\end{array}$ & $\begin{array}{c}\text { dissera } \\
\text { amara }\end{array}$ \\
\hline Frasal & $\begin{array}{c}\text { dizer } \\
\text { amar }\end{array}$ & $\begin{array}{c}\text { dizendo } \\
\text { amando }\end{array}$ & $\begin{array}{c}\text { dizendo } \\
\text { amando }\end{array}$ & $\begin{array}{c}\text { dito } \\
\text { amado }\end{array}$ \\
\hline
\end{tabular}

As formas frasais se caracterizam por eliminar a distinção entre os modos próximo e remoto, como se nota nestes exemplos:

Eu quero que meu filho

Eu quis que meu filho

Meu filho passa de ano se

Meu filho passava de ano se

Eu quero meu filho

Eu quis meu filho

Meu filho passa de ano

Meu filho passava de ano

$\begin{array}{ll}\text { estude } & \text { - próximo. } \\ \text { estudasse } & \text { - remoto. } \\ \text { estudar. } & \text { - próximo. } \\ \text { estudasse. } & \text { - remoto. } \\ \text { estudando } & \text { - próximo. } \\ \text { estudando } & \text { - remoto. } \\ \text { estudando } & \text { - próximo. } \\ \text { estudando } & \text { - remoto. }\end{array}$

O acabado efetivo frasal (no caso, dito e amado) é invariável (quando variável, é adjetivo) e perdeu quase toda sua aplicação, restando-lhe ainda o emprego nas formas compostas do verbo com os auxiliares ter e haver. Duas dessas formas se fossilizaram como preposições: exceto e salvo.

3. Eliminou a categoria de tempo, indicando o momento do fato pelo jogo aspectual e modal. Para os gramáticos, desapareceu o aspecto e ficou o tempo. O erro aconteceu pelo raciocínio simplista dos primeiros gramáticos e perpetuou-se pela tendência tradicionalista dos posteriores: correto é o que já foi escrito. O perfectivo latino (aspecto acabado) era formado pelo acréscimo de 
um sufixo ao radical dos verbos regulares ou por uma variante do radical dos verbos irregulares.
Amare:
amavi $>$ amai $>$ amei
Dare:
dedi > dei

Como foi o sufixo de aspecto que desapareceu, pareceu lógico deduzir que teria também desaparecido o significado de aspecto. $O$ azar dos primeiros gramáticos foi que, contrariamente a uma expectativa racional (eu costumo dizer que toda lingua é idiota), desapareceu o sufixo de aspecto e, concomitantemente, o significado de tempo.

O desaparecimento do tempo verbal deve ser comprovado com exemplos da língua falada:

O carro da mulher dele era vermelho.

Como a forma era é condicionada (modo remoto), tudo vai depender do fator de condicionamento, que pode ser um destes impedimentos:

1. Pintaram o carro com outra cor: o fator impeditivo é um momento no passado. de dono.

2. Venderam o carro, que continua vermelho: o fator impeditivo é a troca

3. O marido ficou com o carro da mulher: o fator impeditivo é ainda a troca de dono.

4. Eles se separaram: o fator impeditivo é a inexistência da mulher dele (por enquanto!).

5. Ele morreu: o fator impeditivo é a tragédia da morte.

6. Ela morreu: continua o mesmo fator impeditivo e a mesma tragédia.

$E$ apenas um desses fatores (o primeiro) é a época passada do fato.

Tenho ainda o diálogo que mantive com uma de minhas alunas, que apontava um prédio vizinho por uma das janelas desta casa (escrevo no computador do nosso Departamento de Lingüística):

-Meu noivo morava naquele prédio.

-Não mora mais?

-Mora, mas não é mais meu noivo.

E eu pensei: que burro!...

Seguindo as regras das nossas gramáticas normativas, ninguém poderia aprender a língua portuguesa: o uso da língua contraria o ensino. Assim, o 
chamado imperfeito, tanto indicativo quanto subjuntivo, é declarado um tempo pretérito. A língua refuta essa doutrina:

Se chovesse amanhã, eu fícava em casa.

Se me desse na cabeça de ir à Europa, o senhor era capaz de me acompanhar? [Machado.]

Acontece que esse enunciado deve ser entendido com base no relacionamento de modos, dado que os dois fatos, chover $\mathrm{c}$ ficar $\mathrm{cm}$ casa, são ambos inacabados:

Se chover amanhã, eu fico $\mathrm{cm}$ casa.

Se chovesse amanhã, cu ficava em casa.

No primeiro caso, o falante considera que pode chover. No segundo, que é impossivel chover. E é evidente que outro falante pode achar exatamente o contrário...

As formas eventuais têm um estatuto todo especial, porque as inacabadas são formas livres, mas condicionadas pelo periodo imperativo, enquanto as acabadas são formas presas e condicionadas pelas acabadas próximas. Ou scja: as inacabadas têm um condicionamento semânticoc as acabadas um condicionamento sintático. No processo subordinativo, todas elas conservam os traços de inacabamento ou acabamento, mas adquirem ainda o traço de posterior (as inacabadas) ou de anterior (as acabadas):

\begin{tabular}{|c|c|}
\hline ACABADO ANTERIOR & INACABADO POSTERIOR \\
\hline $\begin{array}{c}\text { disser } \\
\text { amar }\end{array}$ & $\begin{array}{c}\text { diga } \\
\text { ame }\end{array}$ \\
\hline
\end{tabular}

E falta ao português o cixo da simultancidade, que seria uma forma nem anterior, nem posterior, assinalada pela linha que separa os dois campos. Essa lacuna deixa os falantes indecisos: faltando a forma simultanea, é preciso escolher uma das existentes, acabada ou inacabada. Tenho feito um teste entre os colegas a quem tenho dado cursos de prática de ensino de Lingua Portuguesa em diversas partes do Brasil e, quando havia um grande número de participantes, a hesitação era percebida com facilidade, bem como a escolha diversa. Eu lhes 
pedia que completassem os enunciados seguintes com a forma que lhes parccesse melhor. E vinha um lembrete final:

Completem o pensamento com alguma forma do verbo chover e, por favor, pensem pouco e falem logo bem alto!...

O teste era este:

Saia antes que

Saia depois que

Saia assim que

As duas primeiras, todos respondiam a elas pronta e corretamente:

Saia antes que

Saia depois que chova.

chover

A última, era uma lástima, pois a maioria ficava calada e a minoria se dividia entre uma coutra forma, manifestando-se apenas depois de um razoável lapso de tempo:

Saia assim que

chova

chover

O motivo se percebe com facilidade: havia a necessidade de uma escolha mais complexa porque falta a forma típica para o relacionamento entre os dois fatos (saida e chuva).

Também as formas acabadas próximas nem sempre denotam o passado, ainda que este seja o mais comum, dado que é o passado que, com a máxima freqüência, encerra os fatos acabados. Machado de Assis nos apresenta uma prova cabal:

O que for saindo, saiu.

E me parece evidente que o que for saindo ainda não saiu... O exemplo que eu dou é uın caso típico de sala de aula de primeiro ou de segundo grau (e de terceiro também, desafortunadamente):

Fazemos a prova amanhã, mas aviso desde hoje: colou, dei zero !

Novamente, o tempo é futuro: a cola e a nota ainda estão por chegar.

Toda língua apresenta um processo singelo $\mathrm{e}$ um produto complexo: todos a aprendem depressa no estado de graça da família, ainda os menos capazes. Por isso, é preciso que o lingüista descubra a gramática interior que a criança constrói, por obra e milagre de Deus. Ainda hoje (13.04.95), encontrei- 
me com o Prof. Dr. Miodunka, um amigo querido que fiz nas plagas polonesas, agora professor visitante desta Universidade, e ouvi dele:

Nunca vou aprender o português. O verbo ć muito complicado.

E eu the respondi:

Não vai mesmo aprender nunca: já aprendeu.

Agora, o dominio do nosso verbo depende apenas de um ensino correto. Para o falante de língua portuguesa, basta-lhe responder a cinco perguntas nada complicadas:

1. De que é que eu vou falar agora?

A resposta nos fornece o verbo numa forma invariante, que existc apenas em nossa mente e deve ser qualificada pelas perguntas futuras. Suponha-se que foi esta a resposta: andar.

2. O fato é independente?

A resposta afirmativa elimina as quatro formas frasais e a negativa elimina as oito oracionais. Tome-se a resposta afirmativa e nos restam estas formas (simplifico, deixando de lado as possibilidades trazidas pelos morfemas de pessoa): ando, andava, ande, andasse, andar, andasse, andei e andara.

3. O fato é acabado?

A resposta afirmativa descarta as quatro formas inacabadas e a negativa descarta as quatro acabadas. Fiquemos com a resposta afirmativa, que nos deixa estas formas, se pensarmos na resposta anterior: ando, andava, ande e andasse.

4. O fato é eventual?

A resposta afirmativa rejeita as quatro formas efetivas e a negativa rejeita as quatro eventuais. Considerada a resposta anterior e uma resposta negativa para esta pergunta, sobram-nos duas formas: ando e andava.

5. O fato é condicionado por algum fator impeditivo?

A resposta afirmativa exclui as quatro formas próximas e a negativa exclui as quatro formas remotas. Acolhendo as respostas anteriores e tomando para esta pergunta a resposta negativa, resta-nos uma única forna que passamos a usar para completar o nosso pensamento: andava. E componho o enunciado mental:

Eu andava...

Até agora, estudei apenas o sistema verbal do português e o do Esperanto. O deste provocou uma polêmica, que os esperantistas pensam que ocorreu para bem da própria lingua, mas esse foi um erro colossal: a polêmica foi feita para 
me dar o assunto da minha tese de concurso para o provimento do cargo de professor titular de Lingüística desta Universidade... O motivo dessa disputa foi o excesso (que eu adoro) dos particípios, porque a cada uma das formas finitas de emprego independente correspondem dois participios, um subjetivo (é sempre adjetivo do substantivo que funciona como sujeito: é o ativo das gramáticas) e outro objetivo (é sempre adjetivo do substantivo que funciona como objeto: é o passivo das gramáticas). Cito-as traduzindo-as pela forma adverbial, que permite reproduzir melhor o significado de cada uma:

\begin{tabular}{||l|c|c|c|}
\hline konstruas - fato presente & $\begin{array}{c}\text { konstruanta } \\
\text { konstruata }\end{array}$ & - ao construir: & $\begin{array}{c}\text { construindo } \\
\text { sendo construído }\end{array}$ \\
\hline konstruis - fato passado & $\begin{array}{c}\text { konstruinta } \\
\text { konstruita }\end{array}$ & - após construir: & $\begin{array}{c}\text { tendo construído } \\
\text { tendo sido construído }\end{array}$ \\
\hline konstruos - fato futuro & $\begin{array}{c}\text { konstruonta } \\
\text { konstruota }\end{array}$ & $\begin{array}{c}\text { - antes de } \\
\text { construir: }\end{array}$ & $\begin{array}{c}\text { havendo de construir } \\
\text { havendo de ser construído }\end{array}$ \\
\hline
\end{tabular}

Enquanto o emprego das formas finitas é simples (afinal, são apenas cinco), o dos particípios tem causado muito problema, porque a classe dos fatos determina tipos de verbos que interferem na escolha. Waringhien e Kalocsay (1980, p.150) propõem quatro classes de verbos (cito um exemplo típico):

1. Verbo de duração e resultado: konstrui-construir.

2. Verbos de duração sem resultado: ami-amar.

3. Verbos de resultado sem duração: trovi-achar.

4. Verbos hibridos: okupi-ocupar.

Os verbos do primeiro tipo privilegiam o uso do particípio passivo passado e os do segundo quase sempre exigem o do particípio passivo presente, cnquanto os do terceiro requerem sempre o particípio passivo passado. Entretanto, o principio de regularidade do Esperanto postula que toda forma seja possivel, desde que haja possibilidade de ter significado em algum contexto. Por isso, acontece que as conclusões a que chegam esses autores tenham bastantes exceções.

O critério foi muito criticado porque tcm uma aplicação penosa: o verbo muda de classe conforme aparecem complementos, além de que os derivados quase nunca pertencem à classe do primitivo. Com isso, toma-se ainda obrigatório estender o critério aos prefixos, que passam a ter duas classes: a que mantém a classe do primitivo $\mathrm{e}$ a que a altera.

Na minha tese para o concurso de professor titular, propus outra maneira de facilitar a escolha dos particípios: 
1. Verbos em que a interrupção do fato ou o seu término implicam significados diferentes: interromper o fato ou acabá-lo são coisas diferentes masakri, trovi [achar]. Eu os chamo verbos descontínuos. Com eles, é forma do pretérito o particípio passivo das línguas eslavas, germânicas e neolatinas: massacrado [masakrita].

2. Verbos em que a interrup̧ão do fato ou o seu término indicam o mesmo significado - ami, koni [conhecer]. Eu os chamo verbos continuos. Com eles, $\dot{\mathbf{e}}$ forma do presente o particípio passivo das linguas eslavas, germânicas e neolatinas: amado [amata].

A prova são os particípios do Esperanto: masakrita / amata. As línguas citadas têm ambíguo o morfema de participio passivo: ora presente, ora passado.

Como cada uma dessas classes implica interromper ou terminar o fato, o que vale é o verbo com seus complementos, importando que sejam antes classes do fato que classes do verbo. Com isso, o paradoxo do imperfectivo, apontado por Dowty (apud Godoi, 1992, p. 41), parece ser apenas um efeito da teoria adotada, induzida por uma restrição cultural da língua do autor, em que se ignora a diferença entre o imperfeito c o perfeito do indicativo: de fato, a todo estava ...-ndo corresponde necessariamente um esteve ...-ndo, nem sempre o perfeito do indicativo. Basta considerar as sentenças formadas com o verbo escrever, que pode ter um uso intransitivo (verbo contínuo) ou transitivo (verbo contínuo):

O professor escrevia muito.

O professor estava escrevendo muito.

O professor escrevia um artigo.

O professor estava escrevendo um artigo.

O fato contínuo das duas primeiras sentenças permite concluir que o professor escreveu, dado que a interrupção ou o término produzem o mesmo efeito, enquanto o fato descontinuo das duas outras impede qualquer inferência, porque existem duas possibilidades que dependem de algum informe complementar para se chegar à verdadeira:

a) Interrompendo o trabalho, nenhum artigo terá sido feito: neste caso, o professor não escreveu um artigo.

b) Terminando o trabalho, o artigo terá sido feito: neste caso, o professor escreveu um artigo.

E o mesmo ocorre com muitos outros verbos, desde que possam constituir fatos contínuos ou descontínuos conforme a sua regència. 
O Esperanto oferece um teste fácil para distinguir uma e outra classe de verbo, com a qual se analisa a igualdade e a desigualdade entre os particípios passivos presente e passado.

A desigualdade implica verbos descontínuos:

Ne plu konstruata $\checkmark$ konstruita

[Não sendo mais construido $\sqrt{ }$ construido]

A igualdade indica verbos contínuos:

Ne plu amata $=$ amita

[Não sendo mais amado $=$ desamado]

Os verbos hibridos devem, na verdade, ser considerados formas homônimas:

Okupi ${ }^{1}$ - Preni en posedon [tomar posse]

Okupi $i^{2}$ - Teni en posedo [manter a posse]

O primeiro pertence à primeira das minhas classes: é um verbo descontínuo. Parece evidente que, ao fazer a ocupação de uma cidade, o exército pode levar a cabo a operação, e a cidade fica ocupada, ou simplesmente interrompê-la, e a cidade fica livre do inimigo que a sitiava:

La armeo okupas la urbon. - O exército ocupa a cidade.

O segundo deles pertence à segunda:

La libroj okupas la tablon. - Os livros ocupam a mesa.

Terminar essa ocupação ou interrompê-la vem a ser o mesmo: a mesa fica limpa, o que nunca acontece com a minha...

Os participios passivos podem aparecer com qualquer dos verbos do primeiro tipo, desde que se queira o significado de ação em curso, ação acabada ou ação apenas intencionada:

La pordo estis fermata, sed mi intermetis piedon.

[A porta estava sendo fechada, mas eu entremeti o pé.]

La pordo estis fermita, kaj mi ne povis eniri.

[A porta foi fechada e eu não pude entrar.] 
La pordo estas fermota post minutoj.

[A porta está para ser fechada dentro de minutos.]

Os particípios do segundo tipo impedem o uso do particípio passado passivo, a menos que se queira proceder grosseiramente, porque esse participio insiste sobre o período em que o fato deixa de existir, enquanto a negação do particípio presente passivo alude ao tempo $\mathrm{em}$ que o fato existia:

Jen amata virino. [Eis uma mulher amada.]

Jen *amita virino. [Eis uma mulher que foi amada c agora é desamada.]

Jen amota virino. [Eis uma mulher que se vai amar.]

O motivo ć claro: o particípio passado indica sempre o que aparece depois do fato. Neste caso, ao fím do amor ou à sua interrupção segue-se o esquecimento ou o desamor.

Entretanto, mais que a falta de delicadeza, o participio passado passivo tem uso restrito com os verbos continuos porque o significado dessa forma se distancia demais do significado básico do verbo, dado que indica o tempo em que o fato deixou de existir:

Akompanata: acompanhado (cm companhia de alguém).

Akompanita: desacompanhado (que perdeu a companhia de alguém).

E ainda mais. Em alguns casos, o participio passado se torna ambiguo: acontece com os verbos híbridos, que pertencem a qualquer das classes, dependendo do contexto. E parece mesmo cômico o que se dá com eles:

Okupital ocupado [neste, nesse ou naquele momento].

Okupita $^{2}$ : agora ou então desocupado.

Apenas o primeiro deles é empregado.

O erro provém de que também os gramáticos do Esperanto pensam que a língua tenha tempo, quando ela trabalha com aspecto, que indica as épocas passada, presente e futura apenas indiretamente, sempre que se trata de uma forma verbal finita. Os participios, entretanto, nunca indicam qualquer das épocas, mas apenas o aspecto, como se pode comprovar com os equivalentes de lingua portuguesa:

Konstruata - em construção no passado, no presente ou no futuro; que está, estava ou vai estar sendo construido.

Konstruita - pronta no passado, no presente ou no futuro. 
que se construiu ou se terá construído.

Konstruota - projetada no passado, no presente ou no futuro; que se ia ou se vai construir.

De resto, é o que acontece com os adjetivos: cada um deles apenas permite que se qualifique ou caracterize o referente, sem indicar nada sobre o momento de que se trata, cvidenciado somente pelo verbo finito empregado na sentença. Como adjetivos de uma língua absolutamente regular, os particípios têm o mesmo estatuto.

Ainda que feito para o Esperanto, que pratico desde 1947, o critério de fatos contínuos ou descontínuos parece que se aplica também a outras línguas, porque apela diretamente para um acidente possivel do fato. $\mathrm{O}$ critério mais comum, provindo de Aristóteles e modificado nestes dois últimos séculos, depende do significado genérico de grupos de verbos: estados, atividades, cumprimentos e outros, deixando sem criticar o fato de que o cumprimento de uma ação é também uma atividade... E adianta pouco a tentativa de subdividir essas classes: verbos homogêneos ou heterogêneos, pontuais ou durativos. $\mathrm{E}$ muito menos socorre o pesquisador o apelo a mundos possíveis, ou mundos de inércia (apud Godoi, 1992, p. 41-42).

A língua inglesa impede a forma progressiva (to be ...-ing) com os verbos contínuos. Essa restrição é cultural e parece provir de que essa língua despreza o fator de tempo total ou parcial que distingue os verbos ser e estar, mantendo para ambos um verbo único. Com isso, também os verbos contínuos ficam afetados, porque interrompê-los equivale a identificá-los como um estar, cnquanto levá-los a cabo implica um ser. Diferentemente, os verbos descontínuos aceitam a forma progressiva para se transformarem em continuos. A existência de ambos (ser, verbo de tempo total, e estar, verbo de tempo parcial) permite transpor esse fator distintivo para os outros verbos contínuos:

Eu sei o que devo fazcr.

Eu estou sabendo o que devo fazer.

E agora, por último, mas em primeiro lugar do meu agradecimento mais sincero, devo dizer que esta conversa comigo mesmo (e com algum leitor) me vcio à mente durante a leitura da tese de doutorado da Professora Elena Godoi: Aspectos do Aspecto, que admirei desde o título. 


\section{RESUMO}

Este estudo pretende levantar os problemas apresentados pelos sistemas verbais das linguas românicas, cuja evolução as afastou fortemente do latim. São propostas novas definiçōes para as categorias verbais de tempo, modo e aspecto, e examinadas as transformações, a que eles ficaram submetidos ao longo de sua história. Especialmente são vistos os sistemas sucessivos que apareceram no latim vulgar lusitãnico, no romanço galego-português, na língua arcaica e na moderna, com uma rápida demonstração da reordenação dos sistemas para readquirir o equilibrio perdido.

Palavras-chave: tempo, aspecto, modo.

\section{RESUMO}

Jena studo pretendas levi la problemojn truditajn de la verbosistemoj de la romanikaj lingvoj, kies evoluo ilin forte malproksimigis de la latina. Estas proponataj novaj difinoj por la verbaj kategorioj de tempo, modo kaj aspekto, kaj ekzamenataj la transformoj, al kiuj ili estis submetataj en la longo de ilia historio. Speciale, estas vidataj la sinsekvaj sistemoj, kiuj aperis en la luza latina vulgara, la praportugala, la arkaika kaj la modema lingvo, kun rapida demonstro de ties reordigo por rehavigi la iam perditan ekvilibron.

\section{ZUSAMMENFASSUNG}

Diese Arbeit hat vor die Probleme darzustellen, die die Verbsysteme der romanischen Sprachen aufweisen, deren Entwicklung sie stark vom Lateinischen getrennt hat. Es werden neue Definitionen für die Verbkategorien Tempus, Modus und Aspekt vorgeschlagen und die Transformationen geprüft, die diese Kategorien im Laufe der Zeit beeinflusst haben. Es werden hauptsächlich die hintereinander vorkommenden Systeme gezeigt, die im lusitanischen Vulgärlatein, im Galicisch-Portugiesischen und archaischen und modemen Sprache vorkommen, mit einer kurzen Vorstellung der Neuordnung der Systeme um das verlorene Gleichgewicht zurückzugewinnen. 


\section{REFERÊNCIAS BIBLIOGRÁFICAS}

BACK, Eurico; MATTOS, Geraldo. Gramática construtural da língua portuguesa. São Paulo : FTD, 1972.

GODOI, Elena. Os aspectos do aspecto - tese de doutorado. Campinas : autor, 1992.

MATTOS, Geraldo. Lingvistika priskribo de la verbo en esperanto. In: Serta gratulatoria in honorem Juan Régulo. La Laguna : Universidad de Laguna, 1987.

SANTOS, Geraldo Mattos Gomes dos. Discussão da polêmica dos particípios em esperanto. Curitiba : autor, 1986.

WARINGHIEN, Gaston ; KALOCSAY, Kalman. Plena analiza gramatiko. Rotterdam: UEA, 1980. 